first the fact that the agency is charged with rationalising the aerospace facilities of Europe and in particular "improving the world wide competitiveness of European industry"-in the words of the convention. An Industrial Policy Committee (IPC), which will take a long, hard look at the aerospace structure and performance of each member country, is already being formed. "It may need to tell some firms to drop cut" - in the transponder/repeater field, for example-should there prove to be a glut of manufacturers. The IPC will hold its first meeting this summer and by the end of the year there should be some answers.

The other aspect of rationalisation is the pooling of national space projects. Gibson is much encouraged by the change in attitude that was apparent at the meeting of European space ministers in April. Everybody expressed themselves keen to "play the card of Europe", in the French minister's words. Previously, member countries upheld national and European interests at the same time. "The ESA objectives cannot be brought off without sacrifice", says Gibson, "and up till now 'sacrifice' is something someone else makes." An early test may be whether the Germans are willing to pcol their direct-television broadcast satellite project.

Gibson is not a man for personal publicity though he seems to recognise the need for such an organisation as the ESA to have a face. He is rather clear on the management style that he intends to promote. He envisages a sharpening and streamlining of management responsibility, what he calls a much more integrated management approach. This can come about now that the full directorate (of nine) has been formed-five appointments had to await the decision on the director-general because of the distribution of jobs among member states. "People think it has all been cooked", says Gibson. "It has-but not in the sense that member countries have offloaded their duds on us. Today we have no "diplomatic passengers'". His integrated management philosophy he describes as "simplicity born of desperation". He practises a "wide discussion" of any problem among the directors and all other staff involved-. an entirely free debate where everyone chips in but once the executive decision is taken he requires complete loyalty of execution. "I expect whole-hearted acceptance even if $49 \%$ didn't want that direction beforehand." And if not, then they can go and peddle their matches somewhere else. He admits he feels "very strongly" about a "team approach" but not in terms of vagueness-the term team is often used to shift responsibility on to someone else.
"We simply cannot afford to be transformed into a woolly civil service-type outfit where people are carefully housed [for example] when they are not making a contribution."

How is any tendency of this kind to be prevented? To start with he considers work style of the ESRO-ESA type of operation is an asset. "In contrast to other organisations, for instance the OECD, there is a direct result-hardware." $\mathrm{He}$ explains that there is little paperwork involved and a rigid timetable. If things slip in preparing a space project everything goes awry. Consequently people at ESRO work very hard; they are enthusiasts and think nothing of working late into the night. "Most of our people are sold on space and the level of professional scrounging is extremely small." The way to keep things this way is above all to be extremely careful over recruiting. Gibson comments, however, that it is now eight years since people were recommended by member governments "to get them out of the way". The present standard of new staff is very high. The other aspect is tenure: "We need to steer a mid-course between security and bureaucracy". He sees the long-term contract as the key, and although the appointment of ESRO's director-generals was for three years, one senses that Gibson may be set for something more like a decade.

The stature of Europe-in-space is something that Gibson takes very seriously. He feels that the outside world does not appreciate Europe's capability. "No one doubts that Hughes, for instance, can do the whole thing" but it does not occur to them that western Europe as an entity can.

\section{ESA looks ahead}

IN a few weeks the first satellite under the European Space Agency's new name will be launched.

This year's satellite, COS-B, will carry a single large experiment, capable of detecting gamma rays with energies exceeding $20 \mathrm{MeV}$. The next scientific satellite planned for launch (in 1976) is GEOS, which will continue the theme of several European satellites in carrying out integrated studies of the magnetosphere. The earlier HEOS II satellite was the first to measure the magnetospheric properties of the polar cusp region, and also discovered the plasma mantle; HEOS I (now in its seventh year) continues to provide information about related phenomena.

But it is the other satellites in ESA's present programme which really point the way ahead for science in space. This path is very
The opportunity offered by the coincidence of the biennial Paris Air Show and the signing of the ESA Convention has not been missed, for example, and a three-day conference and demonstration of European capabilities has been put on for the benefit of key visitors, including some ministers. Non-ESRO projects such as Britain's defence communications link Skynet and the Franco-German regional satellite Symphonie as well as ground-stations were on view to show that Europe has the capability today to "do the whole thing". Part of this preoccupation is concerned with Spacelab, which Europe is building for the American Shuttle programme for the 1980 s and to which it will contribute half the first scientific payload. Gibson feels there is a danger of making propaganda over Europe's first entrance into manned spaceflight, as almost equal partners with the USA. Proper use of the possibilities Spacelab offers is much more important and he is not convinced that what this means is any better understood in the USA than in Europe. Spacelab experiments will cost less and the transfer from drawing board to flight fulfilment will be much quicker than the present seven years. They need not be miniaturised nor automatic. Integrating this highly complex programme is a daunting problem which Gibson has spent a lot of time thinking over. Financial, institutional and payload use, as well as development, all require to be effectively tried together.

The success of Spacelab would undoubtedly be the ultimate justification of the new agency - and the climax of Roy Gibson's career as director-general.

much one of collaboration. On the International Ultraviolet Explorer satellite, also due for launch in 1976 , ESA will be collaborating with both NASA and the United Kingdom (so the UK, as a member of ESA will be collaborating with itself!). This satellite should be accessible to any astronomer in much the same way that telescopes on Earth are used by many different members of the astronomical community.

More collaboration with NASA is involved in the International Sun Earth Explorer (ISEE) project, planned for 1977, which also follows the European tradition of investigating the interplanetary medium and Sun-Earth links. And ESA's biggest project, the Spacelab, ties the future of European space research even more closely to that of NASA; so the last satellite in the present programme, EXOSAT, is likely to be ESA's last independent scientific fling, for a good few years at least. 